\title{
Globalização financeira e volatilidade de capitais: a busca de uma alternativa racionalista
}

\author{
PEDRO LUIZ DALCERO*
}

A globalização financeira e a volatilidade de capitais vêm sendo objeto de preocupação da política externa brasileira. O Presidente da República em carta encaminhada ao presidente francês Jaques Chirac durante o processo de consultas que antecedeu a reunião do G-7 em 1996, Cúpula de Lyon, manifestou a prioridade que o tema assume para a agenda internacional.

O objetivo desse artigo é discutir a globalização financeira. Serão expostos aspectos relativos ao fenômeno em si, suas características históricas. Posteriormente, será apresentada uma interpretação da globalização financeira sob o ponto de vista do paradigma realista da teoria das relações internacionais. A globalização financeira não elide a capacidade dos Estados de intervirem nos mercados de capitais, tornando-se esses, com efeito, campo privilegiado para o exercício das relações de poder. Por fim, discutir-se-á a proposta do economista norte-americano James Tobin, a criação de um imposto sobre transações financeiras internacionais, na tentativa de demonstrar que tal proposta preenche requisitos que a classificam como "racionalista", no âmbito do que se convencionou chamar de "mercado internacional de capitais".

\section{O que entender por globalização financeira?}

O termo "globalização" não é consensual. Porém, mesmo analistas que descrêem na existência do fenômeno - vendo na palavra um signo ideológico -, reconhecem que na esfera das transações financeiras internacionais atingiu-se algo inédito e de abrangência global ${ }^{1}$. O que distingue a globalização financeira contemporânea dos grandes fluxos de capitais do início do séc. XX é a prevalência,

Rev. Bras. Polít. Int. 40 (2): 131-143 [1997]

* Diplomata. O artigo expressa opiniões pessoais que não refletem necessariamente a posição do Ministério das Relações Exteriores. 
em nossa época, do fluxo de capitais privados. Naquele outro período a maior parte dos capitais migravam apenas no sentido bilateral e na forma de empréstimos, garantidos por títulos públicos emitidos pelos países industrializados. A partir da década de 60 esse cenário sofreu uma mudança qualitativa. Como salienta Eric Hobsbawm² ${ }^{2}$ o surgimento do eurodólar representa a primeira vez na história em que um grande volume de uma determinada moeda passava a ser transacionada fora da base territorial e do controle da sua respectiva autoridade monetária. Entre os problemas gerados por esse fenômeno estava a capacidade desse mercado "criar" moeda, na medida em que empréstimos bancários eram concedidos em dólares fora do âmbito de regulação do Federal Reserve, o banco central dos Estados Unidos.

A hegemonia econômica-financeira americana não foi particularmente afetada pelo fenômeno do Euromercado. As empresas norte-americanas com filiais na Europa beneficiaram-se dessa situação, fazendo empréstimos, alternadamente, em cada lado do Atlântico, dependendo da taxa de juros que lhe fosse mais conveniente ${ }^{3}$. Ampliavam-se, contudo, as fragilidades estruturais do sistema de Bretton Woods que haviam sido apontadas por Robert Triffin (Paradoxo de Triffin): um afluente mercado de capitais dolarizado no continente europeu contribuía, por meio do mecanismo de geração de moeda com empréstimos bancários, para aumentar a exposição a que o dólar estava submetido.

Nesse contexto, Susan Strange analisa o processo de criação e crescimento exponencial do mercando financeiro internacional. Strange faz um levantamento circunstanciado, reunindo informação jornalística e análise histórica, das decisões (ou não-decisões, como prefere) que deram ensejo ao mercado internacional tal como o conhecemos hoje. A análise da autora ressalta o vínculo existente entre as motivações políticas dos governos e a forma como atuaram ou deixaram de atuar sobre esse mercado. Estabeleceu-se assim uma espiral de desresponsabilização sobre os mercados que seria acentuada com os sucessivos choques do anos 70. Por exemplo, os pretrodólares foram investidos no Euromercado devido a desconfianças dos árabes em relação aos norte-americanos, apesar da Arábia Saudita haver tornado-se o maior financiador do déficit no balanço de pagamentos dos EUA, comprando títulos do tesouro ${ }^{4}$; a confrontação do Ocidente com a OPEP fez com que países em desenvolvimento não exportadores de petróleo fossem diretamente prejudicados.

No que diz respeito à decisão de pôr fim à paridade ouro-dólar, resultando no desaparecimento do "emprestador de última instância” e na adoção de taxas de câmbio flutuantes ${ }^{5}$, tanto Strange como Robert Gilpin ${ }^{6}$ vêem nesse episódio um ato de afirmação de poder dos Estados Unidos - visão, contudo, distinta de outros teóricos das relações internacionais que ali identificam um sinal de declínio da hegemonia norte-americana ${ }^{7}$. A potência hegemônica alterou substancialmente as regras de um sistema monetário que havia constituído, a partir do momento 
em que esse sistema passou a apresentar o que era percebido como disfunções que fragilizavam sua condição hegemônica. Nesse sentido, a decisão de deixar as taxas de câmbio flutuarem livremente não advém de uma "falta de liderança" norte-americana, mas de uma reafirmação de poder dos Estados Unidos transferindo o custo de manutenção do sistema para seus aliados. Para Gilpin os EUA foram os primeiros a perceber a natureza do mercado que se expandia, manipulando-o segundo seus interesses econômico-financeiros e estratégicos ${ }^{8}$.

O cenário nos anos 80 foi marcado pela crise da dívida dos países em desenvolvimento. Mais uma vez prevaleceu o tratamento ad hoc do problema de forma a manter os credores em posição de poder relativo. Durante todo o período de Bretton Woods não foi estabelecido um mecanismo formal para tratar de "crises da dívida" exatamente porque países credores nunca abriram mão da decisão de equacionar essas crises segundo seus interesses políticos.

Os mercados financeiros na década de 80 constituíram-se de forma essencialmente distinta dos mercados de Bretton Woods, passaram a ser transacionados muito mais créditos (equities) do que ações e títulos públicos. A partir da crise da dívida em 1982 o mercado passou a financiar mais empresas transnacionais do que países em desenvolvimento. Cresceu também, no período, o que a autora denomina "significant ignorance", isto é, atividades importantes do sistema bancário internacional deslizaram para fora do controle de quaisquer autoridades monetárias. ${ }^{9}$

A principal razão para essa redução da capacidade regulatória dos Estados foi a internacionalização das atividades bancárias, aliada ao fato de instituições não bancárias (corretoras, por exemplo) terem começado a realizar atividades essencialmente bancárias.

Deve-se matizar, entretanto, essa interpretação relativa à ignorância dos governos ou sua à capacidade regulatória. Estudos mais recentes têm demonstrado que os governos estabelecem controles sobre os fluxos de capital, segundo critérios de conveniência política e econômica. No mesmo sentido, foram criadas redes de segurança para monitorar e estabilizar o mercado quando necessário ${ }^{10}$.

Um ponto apenas superficialmente tratado por Strange é analisado por outros autores: o impacto da revolução tecnológica sobre a atividade bancária. Com efeito, o setor financeiro foi o que mais se beneficiou dos avanços na tecnologia da informação:

"By developing the most advanced foreign-exchange software, Bankers Trust was able to achieve a ten-second advantage over other traders, enough time, according to a 1987 Office of Technology Assessment study, to execute four or five trades. The opportunity to react to new information a few seconds ahead of the market can be worth billions."11 


\section{Uma interpretação realista do sistema monetário internacional}

Supõe-se que o surgimento de uma economia global reduz o escopo de ação dos Estados, que ficam submetidos ao "poder de veto dos mercados financeiros”12. Essa interpretação é adequada para explicar a crise das políticas de molde keynesiano implementadas no pós-guerra. Com efeito, o volume de capitais voláteis circulando na economia internacional constitui um fator de desestabilização das economias nacionais. Um aumento na taxa de juros, por exemplo, pode atrair um volume excessivo de capitais que precisam ser convertidos em moeda nacional, podendo gerar expansão da base monetária e inflação, efeitos que se quer combater com o aumento dos juros e que eram alcançáveis no ambiente econômico reinante até a década de 70. Essa nova interação entre as economias nacionais e a economia internacional, segundo Strange, é o principal motivo para a crise dos modelos keynesianos de regulação. ${ }^{13}$

Um outro viés interpretativo das relações econômicas entre os Estados é dado por Jonathan ${ }^{14}$. Esse autor analisa todas as crises monetárias do séc. XX até a crise nigeriana de 1968, apontando os casos em que houve exercício do "poder monetário", ou perdeu-se a oportunidade para o exercício desse poder.

Segundo Kirshner, o poder monetário internacional repousa na interseção das relações monetárias internacionais com a diplomacia econômica. Exerce-se por meio de três formas distintas: manipulação de moedas (currency manipulation); dependência monetária (monetary dependency); e ruptura sistêmica (systemic disruption). A manipulação de moedas é a ameaça ou ação deliberada no sentido de atingir a estabilidade e valor da moeda alvo (target currency). Trata-se do instrumento mais simples de poder monetário e de uso mais comum e diversificado, além de ser flexível, podendo variar de intensidade; indo da simples sinalização até a desestabilização de países alvos. Uma "negative currency manipulation,” por definição, altera o valor desejável da moeda para o país alvo ${ }^{15}$. Constitui um tipo de ação extremamente focada sobre o país alvo, pode ser feita de forma pública ou secreta e interage com o "bandwagon", ou com movimentos contrários do mercado, na busca de seus objetivos.

A dependência monetária é o uso do poder monetário na exploração de relações assimétricas entre Estados. No contexto das relações monetárias essa dependência manifesta-se normalmente com a criação de "zonas” formais ou informais que adotam determinado padrão monetário. No plano interno, intrazona, a natureza do poder resulta do controle ampliado que o país emitente da moeda dominante (home country) detém para manipular outras moedas da zona. Sob o ponto de vista externo, a zona monetária isola os países participantes de influências exteriores e pode servir de base para a mobilização de recursos. 
A ruptura sistêmica constitui-se em ameaça de romper arranjos monetários, ou na sua ruptura efetiva, com o objetivo de destruir o sistema, ou extrair dele maiores benefícios. Antes que a ruptura ocorra de fato pode haver uma redistribuição de prestígio e benefícios entre as moedas do sistema. Dois tipos de países são os mais vulneráveis à ruptura sistêmica: os países pequenos, que beneficiam-se de determinados arranjos e têm um interesse na estabilidade sistêmica; e os "países emitentes" (home countries) que valorizam os ganhos advindos do papel de líder.

Kirshner compara o poder monetário com o que identifica como outros instrumentos de coerção econômica: a cooperação ao desenvolvimento (aid); o comércio e a diplomacia financeira. $\mathrm{O}$ autor classifica esses instrumentos segundo critérios que consideram a vulnerabilidade do país alvo à coerção econômica, o estabelecimento de coalizões contrárias no país que exerce a coerção (home states) e a autonomia do poder executivo no "home state" para o exercício de cada tipo de coerção econômica. Sua constatação é de que o poder monetário é o instrumento mais eficaz de poder dos Estados. O Executivo pode fazer uso dele sem afetar, no âmbito doméstico, o interesse de grupos ligados ao país alvo e que possam pressionar o Legislativo (como ocorre com a coerção comercial). A coerção monetária pode ser exercida sem que lhe seja dada publicidade - podendo inclusive ser secreta - uma vez que não requer legislação específica. E, do lado do país alvo, bruscas variações no valor da moeda são sentidas de forma tão grave que podem desestabilizar governos.

Outra constatação de Kirshner é relativa à dependência que esses instrumentos de poder têm em relação à existência de uma economia de mercado internacional. O comércio e a cooperação ao desenvolvimento, por exemplo, são menos dependentes da existência de uma economia global. Relações comerciais bilaterais foram estabelecidas ao longo da história criando, muitas vezes, laços de dependência. Apesar de ser um fenômeno moderno, a cooperação ao desenvolvimento pode operar sem apoiar-se numa economia global. A diplomacia financeira e o poder monetário, a seu turno, são muito mais dependentes da existência de uma economia de mercado internacional. Registra-se através da história, observa o autor, casos do exercício de coerção monetária por meio da denegação do acesso a moedas internacionais ou operações de sabotagem, utilizando-se do mercado negro de moedas. Mas a coerção monetária exerce-se de forma muito mais constante, explícita e eficaz numa economia de mercado internacional como a surgida no séc. XX.

Entre as conclusões do autor algumas apresentam particular relevância. Devido às relações monetárias serem as mais hierárquicas das relações econômicas internacionais, há um reduzido número de agentes exercendo o poder monetário. O sistema monetário contemporâneo conta assim com apenas três atores efetivos: os Estados Unidos, a Alemanha e o Japão. Ao mesmo tempo, 
existe uma tendência à dispersão desse poder. "Relative power will shift away from the United States toward Germany and Japan. Once again, this development will increase the salience of monetary power in the international system" ${ }^{\prime \prime}$. Esse movimento é visto como fonte de maior instabilidade para o sistema, na medida em que significa um aumento na capacidade dos atores menores em exercer a coerção monetária, ao passo que os Estados Unidos podem sentir-se, igualmente, menos impedidos de fazê-lo. Finalmente, Kirshner considera a expansão dos mercado de capitais ocorrida nas últimas décadas.

"The power of the market has grown fantastically in the last twentyfive years, and technological developments have integrated those markets to a great extent than ever before. Both of these developments increase the opportunities for the practice of monetary power, and thus suggest that it will become an increasingly common feature of international politics. "17

A contribuição de Jonathan Kirshner, entretanto, não faz desaparecer um tremendo viés de seu trabalho. Apesar de escrever nos anos 90, Kirshner não considera o fim da paridade ouro-dólar, decidida pelo governo Nixon em 1971, como um caso de ruptura sistêmica. Com efeito, esse episódio constitui um caso flagrante de ruptura sistêmica promovida pelo "home country" do sistema monetário internacional. É certo que o autor faz a análise de casos somente até 1968, mas sua obra intriga pela ausência de qualquer referência a 1971 como um tipo particular de ruptura sistêmica, perpetrado pelo núcleo do sistema. Nesse sentido, as análises de Gilpin e Strange ${ }^{18}$ são mais esclarecedoras ao reconhecer na decisão dos Estados Unidos uma reafirmação da hegemonia.

Na década de 90, outro exemplo de ruptura sistêmica, dessa vez de um sub-sistema, ocorreu quando da decisão do Bundesbank de elevar a taxa de juros para conter efeitos inflacionários dos gastos com a unificação alemã. A conseqüente migração de capitais para a Alemanha rompeu com os dispositivos do Sistema Monetário Europeu, fazendo que a Libra e a Lira fossem retiradas da serpente monetária.

\section{A busca de uma alternativa racionalista}

Os autores até aqui tratados fornecem um instrumental para compreender-se a globalização financeira por meio do entendimento das relações de poder. Kirshner, Gilpin e Strange não crêem que o poder do Estado desaparecerá no cenário de uma economia globalizada. Susan Strange, sobretudo, em "Toward a Theory of Transnational Empire”, fornece um quadro analítico sobre a natureza do poder dos Estados Unidos, que determina a "estrutura" do exercício do poder.

Sob o ponto de vista prático, entretanto, são poucos os elementos fornecidos pelos autores para a ação diplomática de países com escassos recursos 
de poder. Constata-se apenas a exigüidade crescente desses recursos e os riscos decorrentes ora do exercício puro do poder, ora da instabilidade adquirida pelo sistema.

No plano teórico, quando contrastados com Hedley Bull em "The Anarchical Society", 19 aflora a incongruência de perspectivas analíticas tão distintas. Poder-se-ia dizer que obras de Bull e Gilpin - dois trabalhos similares, que procuram dar conta de forma sistêmica de seus temas - são antípodas conceituais, tratam de assuntos absolutamente separados que nunca se encontram. Os imperativos da ordem na política mundial são, no entanto, condicionados pela economia política das relações internacionais.

Dentro dos limites deste artigo, procurar-se-á então analisar a proposta de um imposto sobre transações financeiras internacionais, a proposta Tobin, como uma proposta racionalista para a globalização financeira.

Quando teve fim o regime de taxas fixas de Bretton Woods, o pensamento econômico dividiu-se sobre seus impactos. Milton Friedman, ao lado da maioria dos economistas, afirmou que os governos passariam a ter muito mais liberdade para conduzir políticas macroeconômicas sob um regime de taxas flexíveis. James Tobin $^{20}$ discordava desse quase consenso e, já início dos anos 70, alertava para as dificuldades inerentes à administração de políticas macroeconômicas num ambiente em que volumes significativos de capital realizavam rápidos movimentos transfronteiriços. Em janeiro de 1972, lançou a proposta de um imposto sobre o mercado de câmbio. A idéia consiste em taxar todas as operações de câmbio realizadas em virtude de transações financeiras internacionais. Ao migrarem de uma economia para outra os capitais são convertidos para o moeda local, o imposto incidiria sobre a operação de conversão de moedas.

Os valores diários negociados nesse mercado de moedas "foreing exchange” FOREX são realmente vultosos, evoluindo de US\$ 18 bilhões no início dos anos 70 para US\$ 150 bilhões em $1987^{21}$. Segundo dados do BIS passaram de US\$ 860 bilhões em 1992 para US\$ 1,230 trilhão em 1995. Trata-se da maior atividade financeira do mundo ${ }^{22}$.

Nos anos 90 dois motivos aumentaram o interesse na proposta Tobin. De um lado, o gigantesco volume de capitais negociados no FOREX gera justificados temores num ambiente econômico de sucessivas crises no sistema: desarticulação do Sistema Monetário Europeu-SME em 1992; crise cambial mexicana em 1994; falência do Banco Barings em 1995; flutuações no SME em 1995/96; e, mais recentemente, a crise asiática. De outro lado, a proposta Tobin foi identificada como um possível gerador de recursos para a cooperação internacional.

A proposta recebeu, assim, atenção inédita desde a sua formulação; foi discutida na reunião da Cúpula Social, em Copenhague, constou das discussões preparatórias à Cúpula de Halifax, reunião do G-7 de 1995, e foi sugerida pelo 
Relatório de Desenvolvimento Humano de 1994, do PNUD ${ }^{23}$. Segundo Barry Eichengreen ${ }^{24}$, aqueles que apóiam o imposto Tobin encontram três tipos de justificativas para a proposta. A proposta Tobin é uma fonte potencial de novos recursos para o desenvolvimento e a cooperação econômica internacional. Parte dos recursos recolhidos a partir da incidência do imposto poderia ser destinada a organismos multilaterais. Outra razão para se implementar a proposta reside na expectativa que a taxação reduziria a volatilidade de capitais. $80 \%$ das transações no FOREX são de "round trips" de menos de sete dias, sendo que $40 \%$ de dois dias ou menos ${ }^{25}$. Finalmente, o terceiro motivo apresentado é que a implementação do imposto vai ampliar a independência das autoridades monetárias na formulação de políticas macroeconômicas.

"Breaking the interest-parity condition (the condition that domestic interest rates may differ from foreign interest rates only to the extent that the exchange rate is expected to change) will allow authorities to pursue different policies than those prevailing abroad without exposing them to large exchange rate movements". ${ }^{26}$

Enfim, motivações sedutoras o suficiente para que a proposta acabasse recebendo maior atenção. Jeffrey Frankel ${ }^{27}$, discute os impactos do imposto sobre a volatilidade de capitais. De acordo com três modelos econométricos examinados por esse autor, que levam em conta diferentes percentuais para o imposto a ser recolhido e a elasticidade da base fiscal (i.e. o mercado FOREX) após a sua incidência, um percentual de $0.1 \%$ ad valorem teria significação reduzida para as movimentações de capital de longo prazo, mas com efeitos consideráveis nas transações de curto prazo. O autor mostra-se cético, entretanto, a respeito da possibilidade do imposto ser instrumental para que os governos recuperem parte de sua independência perdida: "a country can have any two of the attributes of financial openness, currency stability and monetary independence, but it cannot have all three."28

Quanto ao percentual do imposto a ser cobrado, não há consenso entre autores que debateram a proposta ${ }^{29}$. Peter B. Kenen ${ }^{30}$ lembra, por exemplo, que a margem de lucro no mercado FOREX é bastante reduzida, inferior a $0.1 \%$ para a maioria das moedas ${ }^{31}$; logo o imposto não poderia ser superior a $0.05 \%$, ad valorem, para não alterar a estrutura do mercado. Ressalta que, mesmo nessa hipótese, sobre a base fiscal de 1992, seriam recolhidos US\$ 100 bilhões.

$\mathrm{O}$ argumento recorrente sobre a impossibilidade de um imposto de tal natureza diz respeito à existência de paraísos fiscais. Mesmo que as principais economias do mundo subscrevessem um tratado criando o imposto, sua aplicação seria inviável em função da existência de pequenos paraísos fiscais. David Felix, no trabalho "Financial Globalization versus free trade: the case for the Tobin Tax", ${ }^{32}$ demonstra as diferenças existentes entre desenvolver um produto financeiro e registrá-lo em um paraíso fiscal (escapando de taxações nacionais) e transferir todas as atividades de planejamento, comercialização e marketing 
para esses locais. Essa última alternativa é menos comum e mais custosa e funcionaria como um desincentivo para a busca de paraísos fiscais. A tese central desse autor, ademais, é que a instabilidade no mercado FOREX está impedindo a expansão do comércio internacional, dado que gera incertezas sobre os valores comercializados.

Peter Kenen sugere um outro mecanismo para evitar-se a evasão fiscal: sobretaxar todas as transferências de capital para países não signatários do acordo que instituir o imposto. Poder-se-ia, inclusive, estabelecer um taxação inicial punitiva de 5\% para prevenir que bancos e corretoras tomassem a iniciativa de transferir-se para esses países.

Uma proposta como a Tobin envolve complexidades de natureza econômica que extrapolam dos limites deste texto. Sob o ponto de vista político, contudo, ela merece ser analisada com mais atenção. O sistema monetário internacional "guarda um bem público, que é produzido em nível inferior ao satisfatório quando os participantes entregam-se a seus próprios interesses" ${ }^{33}$. Esse sentido de common do sistema monetário internacional parece ser suficientemente válido para justificar iniciativas como a proposta Tobin.

O imposto Tobin, todavia, não pode ser visto como um "imposto global" sugerindo a necessidade de um autoridade monetária supranacional. Com efeito, o imposto Tobin seria, como aponta Inge Kaul (op.cit), um imposto nacional fruto de um acordo internacional, a ser recolhido nacionalmente pelos Estados que deveriam reter parcela substancial de sua arrecadação. $O$ valores envolvidos na proposta Tobin são de grandeza suficiente para representarem um alívio na crise fiscal dos Estados, principalmente dos Estados onde ocorre a maior parte da atividade financeira internacional. Esses fundos devem ser compartilhados, contudo, com algum fundo multilateral.

"Tobin Tax can be implemented effectively only as a collective effort of the international community. If no revenue went to a multilateral initiative of common interest, countries that expected very little revenue from participating, or no revenue at all, would surely defect" ${ }^{34}$.

A destinação desses recursos recolhidos a um fundo multilateral suscitaria uma série de indagações. Por exemplo, que instituição gerenciaria o fundo? $\mathrm{O}$ FMI, o Banco Mundial e o BIS são candidatos naturais, ou deve-se pensar numa nova instituição? Ainda mais importante, sob o ponto de vista de países com economias de porte médio, qual seria o processo decisório utilizado? Enfim, as recorrentes questões de natureza política.

\section{Conclusão}

A proposta Tobin reúne características que representam um divisor de águas conceitual na formulação de alternativas para lidar-se com o que se 
convencionou chamar de globalização financeira. Sua força reside exatamente em que não se contrapõe à lógica da globalização, não procura retroceder de um determinado patamar de integração financeira internacional. Distancia-se, igualmente, do que poderia ser visto como "confrontacionismo" das antigas propostas da Nova Ordem Econômica Internacional. Trata-se apenas de uma iniciativa regulatória para um mercado que apresenta características de barbárie ${ }^{35}$.

No mesmo sentido, a proposta de um imposto sobre transações financeiras internacionais não constitui uma iniciativa de coordenação de políticas macroeconômicas entre as principais economias ${ }^{36}$. Caso venha a ser implementada poderá produzir prováveis efeitos positivos sobre a volatilidade de capitais, a autonomia de gestão das políticas macroeconômicas nacionais e gerar novos recursos para a cooperação internacional. Estará longe, contudo, de representar algo como a criação de um banco central internacional ou uma coordenação estrita entre os Estados emitentes das principais moedas.

Conforme foi afirmado no início desse texto, acredito que o imposto Tobin reúne características de uma proposta racionalista para a globalização financeira. Sua implementação não implica redução da soberania dos Estados, mas num grau de "institucionalização" do mercado internacional de capitais que se aproxima de visões racionalistas. O "poder monetário”, tal como definido por Kirshner, continuaria sendo exercido pelos "home states" de moedas internacionais. A implementação da Tobin representaria, entretanto, um componente a matizar essas relações de poder no campo financeiro e monetário.

Julho de 1997

\section{Notas}

1 HIRST, Paul e THOMPSON, Grahame. Globalization in Question. The International Economy and the Possibilities of Governance, pp. 131-136

2 HOBSBAWM, Eric. The Age of Extremes. P. 278

3 Essa interpretação pode ser encontrada tanto em GILPIN, Robert, The Political Economy of International Relations, como em STRANGE, Susan, Casino Capitalism.

4 GILPIN, Robert, op. cit., p. 315

5 A partir de 1971 o sistema monetário passou a adotar o regime de taxas flutuantes, que só existe em tese, na medida em que os governos não deixam suas moedas flutuarem sem recorrer a mecanismos de intervenção. Esse tipo de flutuação cambial, onde as moedas flutuam mas com intervenções regulares das autoridades monetárias, é chamado de “dirty floating."

6 GILPIN, op. cit., p. 140, e STRANGE, op.cit, pp. 67-68

7 STRANGE, Susan, op.cit., p.67, citando Robert Keohane em “After Hegemony” .

8 GILPIN, op.cit, pp. 315-317

9 LEBLANG, David, "Domestic and Systemic Determinants of Capital Controls in the Developed and Developing World”, International Studies Quarterly, setembro, 1997. Esse autor fornece 
uma análise mais contemporânea, afirma que os países, seja por motivos internos ou externos, estabelecem alguns mecanismos eficazes sobre os fluxos de capitais.

10 LEBLANG, op. cit pp-435-454

11 BARNETT, Richard J. e CAVANAGH, John, Global Dreams. Imperial Coporations in the New World Order, P. 386

12 BELLUZO, Luiz G. de M., “O declínio de Bretton Woods e a emergência dos mercados”, em Economia e Sociedade, p. 19.

13 STRANGE, Susan, op. cit., pp. 77-78 e pp. 136-137.

14 KIRSHNER, Jonathan. Currency and Coercion. The Political Economy of International Monetary Power.

15 A “currency manipulation” é essencialmente distinta dos ataques especulativos ocorridos nos anos 90, embora seus efeitos possam vir a ser idênticos. A primeira é uma ação deliberada, encetada normalmente por um Estado com recursos de poder no sistema monetário internacional. Os ataques especulativos, a seu turno, são o resultado de iniciativas de especulação, coordenadas ou não, de agentes privados.

16 KIRSHNER, op. cit., p. 279

17 KIRSHNER, op.cit, p.280

18 A propósito dos aportes teóricos de Susan Strange e Jonathan Kirshner é mais interessante, todavia, fazer um paralelo entre a formulação de Kirshner sobre poder monetário e o "quadriedro" de poder estrutural: conhecimento, produção, poder militar e finanças - proposto por Strange em “Toward a Theory of Transnational Empire” (Rosenau e Czempiel, 1989:161-176). Como Kirshner estabelece uma distinção entre diplomacia financeira e poder monetário, a tese de Strange deveria ser "atualizada” com a inclusão de mais uma faceta de poder estrutural , sobretudo porque, como demonstra Kirshner, o poder monetário é o poder estrutural por excelência.

19 BULL, Hedley. The Anarchical Society.

20 Prêmio Nobel de economia em 1982.

21 FELIX, David. “Financial Globalization versus Free Trade: the case for the Tobin tax”, UNCTAD discussion papers, n. 108, novembro, 1995.

22 GARBER, Peter, "Issues of Enforcement and Evasion in a Tax on Foreign Exchange Transactions”, em The Tobin Tax. Coping with Financial Volatility, org. Kaul et alii, pp. 129142

23 GRIFFITH-JONES. Stephany. "Institutional Arrangements for a Tax on International Currency Transactions”, em Kaul et alii, op. cit, pp. 143-158

24 EICHENGREEN, Barry. “The Tobin Tax: What Have We Learned?”, em Kaul et alli, pp. 273274.

25 KAUL, Inge et alii. “Overview”, em The Tobin Tax. Coping with Financial Volatility”, em Kaul et alii, pp. 1-15.

26 EICHENGREEN, Barry - op cit 275.

27 FRANKEL, Jeffrey. “How Well Do Markets Work: Might a Tobin Tax Help?” , em Kaul et alii, op. cit. pp. 41-80

28 FRANKEL, Jeffrey. op cit p. 59

29 O PNUD instituiu um grupo de trabalho para estudar a proposta, do qual resultou o livro The Tobin Tax - Coping with Financial Volatility, que reúne a opinião de diversos analistas.

30 KENEN, Peter B. “The Feasibility of Taxing Foreign Exchange Transactions”, em Kaul et alii, op.cit. pp. 109-126

31 Deve-se ter em mente que mais de $72 \%$ das transações em 1992 foram feitas entre "dealers", tendo os restantes sido negociados com instituições não financeiras. O mercado "inter dealer" é tão significativo porque os bancos desenvolveram diversos produtos financeiros (entre eles os derivativos) para se protegerem de exposições em outros investimentos. As grandes empresas 
transacionais também fazem uso de "hedge funds” (fundos de cobertura) exatamente para obterem uma hedge, isto é uma operação financeira para salvaguardar outra operação de qualquer natureza dos efeitos de flutuações inesperadas de preços, juros ou taxas de câmbio. Ocorre que desenvolveu-se toda uma série de produtos de hedge com base em variações de câmbio.

32 FELIX, David, op.cit.

33 AGLIETA, Michel. “O sistema monetário internacional: em busca de novos princípios”, em Economia e Sociedade, op. cit., p. 129

34 KAUL, Inge, em Kaul et alii, op.cit., p. 12

35 George Soros define as finanças internacionais como "fora do alcance da lei, onde predomina a força - e o estado de coisas em que a força predomina é chamado de barbárie”, entrevista concedida à VEJA, de 01.05.96.

36 A proposta Tobin pode ser vista, entretanto, como um a tentativa de "governance" do sistema financeiro internacional. Ver Hisrt e Thompson, op. cit., p. 135.

\section{Bibliografia}

Aglietta, Michel. “O sistema monetário internacional: em busca de novos princípios”, em Economia e Sociedade, Revista do Instituto de Economia da UNICAMP, n. 4, junho de 1995.

Barnett, Richard J. e Cavanagh, John. Global Dreams. Imperial Corporations in the New World Order. Nova York: Simon \& Shusters, 1994.

Belluzo, Luiz G. de M. “O declínio de Bretton Woods e a emergência dos mercados”, Economia e Sociedade, Revista do Instituto de Economia da UNICAMP, n. 4, junho de 1995.

Bull, Hedley. The Anarchical Society. A Study of Order in World Politics. Londres: The MacMillan Press Ltda., 1997.

Eichengreen, Barry. “The Tobin Tax: What Have We Learned?”, em Kaul et alii (org.), The Tobin Tax. Coping with Financial Volatility. Nova York: Oxford University Press, 1996.

Felix, David. "Financial Globalization versus free trade: the case for the Tobin tax", UNCTAD discussion papers, n. 108, novembro, 1995.

Garber, Peter M. "Issues of Enforcement and Evasion in a Tax on Foreign Exchange Transactions”, em Kaul et alii (org.), op. cit.

Gilpin, Robert. The Political Economy of International Relations. Nova Jersey: Princeton Universtiy Press, 1987.

Griffith-Jones, Stephany. “Institutional Arrangements for a Tax on International Currency Transactions”, em. Kaul et alii (org.), op. cit.

Frankel, Jeffrey. “How Well Do Markets Work: Might a Tobin Tax Help?”, em Kaul at allii (org.), op. cit.

Kaul, Inge. The Tobin Tax. Coping with Financial Volatility. Nova York: Oxford University Press, 1996.

Hobsbawm, Eric. The Age of Extremes. Nova York: Phanteon Books, 1994.

Kaul, Inge e Langmore, John. "Potential Uses of the Revenue from a Tobin Tax", em Kaul et alii (org.), op. cit.

Kenen, Peter B. “The Feasibility of Taxing Foreign Exchange Transactions”, em Kaul et alii (org.), op. cit.

Hirst Paul e Thompson, Grahame. Globalization in Question. The International Economy and the Possibilities of Governance. Cambridge: Polity Press, 1996.

Kennedy, Paul M. e Ingomar Hauchler. Global Trends. The World Almanac of Development and Peace. Nova York: The Continuum Publishing Company, 1994. 
Kirshner, Jonathan. Currency and Coercion. The Political Economy of International Monetary Power. Nova Jersey: Princenton University Press, 1995.

Leblang, David A. "Domestic and Systemic Determination of Capital Controls in the Developed and Developing World”, em International Studies Quarterly, vol. 41, n. 3, setembro de 1997.

Strange, Susan. Casino Capitalism. Cambridge, Massachussetts: Basil Blackwell, 1986.

"Toward a Theory of Transnational Empire”, em Rosenau and Czempiel, Global Changes and Theoretical Challenges. Massachusetts: Lexington Books, 1989.

Revista VEJA, de 01.05.96 “A Riqueza Não Dura Para Sempre - O superespeculador alerta para a possibilidade de quebra do sistema financeiro internacional” entrevista com George Soros.

\title{
Resumo
}

Esse artigo discute a contribuição de alguns autores para a compreensão da globalização financeira. A ênfase é dada às relações de poder que permeiam o processo de globalização financeira. A proposta Tobin, de um imposto sobre tansações financeiras internacionais, é apresentada, ao final, como uma alternativa de moldes "racionalista” para a globalização financeira.

\begin{abstract}
This article discusses how some authors understand the process of financial globalization. The emphasis is in power relations which occur within financial globalization. The Tobin proposal, a tax on international financial transactions, is considered, at the end, as a "rationalist” alternative for financial globalization.
\end{abstract}

Palavras-chave: Globalização financeira. Poder Monetário. Imposto Tobin. Key-words: Financial Globalization. Monetary Power. Tobin Tax. 